\title{
METÁFORAS DESVELADAS: ANÁLISE NA LINGUAGEM USADA POR MURILO MENDES EM POESIA E LIBERDADE
}

\section{ARTIGO ORIGINAL}

MONKEN, Priscila Mattos ${ }^{1}$

MONKEN, Priscila Mattos. Metáforas Desveladas: Análise na linguagem usada por Murilo Mendes em Poesia e Liberdade. Revista Científica Multidisciplinar Núcleo do Conhecimento. Ano 05, Ed. 12, Vol. 19, pp. 05-13. Dezembro de 2020. ISSN: 2448-0959, Link de acesso: https://www.nucleodoconhecimento.com.br/letras/metaforas-desveladas

\section{RESUMO}

O estudo do presente artigo relaciona-se com a Semântica. A língua revela a ideia de um pensamento social o qual forma um ato mental. Nesse aspecto, estudaremos um recurso estilístico chamado metáfora. De fato, desde a Poética e Retórica de Aristóteles, escreve-se a respeito de tal fenômeno, entretanto ainda é um desafio para muitos linguistas que propõem explicações diversas. Refletiremos sobre os usos desse recurso linguístico e posteriormente 0 analisaremos na linguagem usada por Murilo Mendes em Poesia e Liberdade. Partindo do pressuposto de que a metáfora está intimamente ligada à linguagem, pesquisamos as diversas tipologias metafóricas, com o intuito de observar o porquê de um uso em detrimento do outro e o efeito que isso ocasiona. Pretendemos mostrar como tal instrumento linguístico se vincula às questões de ordem social e cunho ideológico. Para tanto, iniciamos nossos estudos com uma pesquisa teórica que irá ser ampliada com o avanço dos resultados que buscamos com o intuito de entender melhor a contribuição da metáfora para a interpretação não somente de textos literários como também de todo o universo que

1 Mestrado em Cognição e Linguagem. Especialização em Revisão de textos. Graduação em Letras Português. 
nos cerca. Além disso, os mecanismos da língua poderão ser melhor instrumentalizados a partir deste artigo.

Palavras-Chaves: Metáfora, linguagem, Murilo Mendes.

\section{INTRODUÇÃO}

A metáfora é uma das categorias de mudança semântica mais relevantes. Suas raízes históricas têm início na Antiguidade Clássica com Aristóteles, perpassando ainda pelo crivo de estudiosos de diversas áreas, que lhe conferem status e funções bem diferenciadas.

Enquanto recurso significativo, segundo Stephen Ullmann (1961), em Semântica, é encontrado sob diversos aspectos: "como um fator primordial da motivação, como artifício expressivo, como fonte de sinonímia e de polissemia". Essa diversidade de funções do fenômeno associada à pluralidade de pontos de vista pelo qual é estudado, resulta em inumeráveis definições que muitas vezes não coadunam. Contudo, a metáfora não se limita à linguagem literária, mas encontra-se intimamente ligada à linguagem humana, ou, mais especificamente, à estruturação do pensamento.

Pesquisar metáfora em textos literários é o que quase todos fazem sem dizer, já que qualquer interpretação literária passa pelo desvendamento do texto, de suas imagens e, consequentemente, de suas metáforas. Assim, propomo-nos, neste trabalho, dar um enfoque diferenciado de tudo o que tem sido feito ultimamente. Pretendemos fazer, com o objetivo primeiro de estabelecermos um panorama no âmbito dos estudos linguísticos-literários, um levantamento de algumas conceituações dadas ao termo metáfora por teóricos e estudiosos do assunto, para por fim, escolher a visão de um autor e sob essa ótica, então, desenvolvermos nossos estudos.

A metáfora está notoriamente presente no nosso cotidiano, porém é na linguagem que se manifesta de forma mais contundente. Dessa forma, toda a pesquisa será permeada pela reflexão da linguagem usada por Murilo Mendes em Poesia Liberdade, partindo do pressuposto que a metáfora está intimamente ligada à linguagem. 
Trataremos das diversas tipologias metafóricas presentes em seus textos, com o propósito de observar o porquê de um uso em detrimento do outro e o efeito que isso traz. Será mostrado também como esse recurso linguístico se vincula às questões de ordem social e de cunho ideológico, por intermédio de um levantamento e discussão de expressões metafóricas na obra Poesia Liberdade.

\section{REVISÃO BIBLIOGRÁFICA}

\subsection{DICIONÁRIO DE LINGUÍSTICA E GRAMÁTICA, DE JOAQUIM MATTOSO CÂMARA JR.}

Metáfora é a figura de linguagem que consiste na transferência (gr. metaphora) de um termo para o âmbito de significação que não é o seu; ao contrário da metonímia, não se fundamenta numa relação objetiva entre a significação própria e a figurada, mas sim numa relação toda subjetiva, criada no trabalho mental de apreensão; ex.: 'o último ouro do sol morre na cerração' (Bilac, Poesias, 340). A metáfora apresenta uma função bastante expressiva, já que destaca aspectos que o próprio termo não consegue evocar por si mesmo; deste modo, a última luz do sol não realçaria a tonalidade especial da luz solar ao crepúsculo. Portanto, a metáfora trata-se de um recurso comum na linguagem e essencial na poesia (MURRY, 1951).

A metáfora é um fato de sincronia e só existe quando o termo tem a significação própria nitidamente distinta da do termo que é substituído. Quando figura sistematicamente numa expressão como idiotismo, perde a força evocativa, porque o termo, em princípio metafórico, está idiomaticamente imposto na expressão (ex.: cabeça de alfinete); tem-se então uma fossilização, e a metáfora só se torna patente em formulações ad hoc (ex.: são ideias de uma cabeça de alfinete). Na diacronia, as metáforas entram na evolução semântica e o termo incorpora a significação, de início metafórico, na significação própria, cuja polissemia - a) Aumenta, ou - b) Na, conforme a antiga significação própria - a) Se mantém, ou - b) Se esvai (exs.: a) Serra para 'conjunto de montanhas' e para 'ferramenta'; B) Flagelo (cf. lat. flagellum 'chicote'd). (CÂMARA, 1992: 166). 


\subsection{DICIONÁRIO DE TERMOS LITERÁRIOS, DE MASSAUD MOISÉS}

A metáfora se monta em torno de uma comparação, explícita ou implícita; consiste, então, na comparação entre dois vocábulos ou frases, de que resulta a transformação de sentido de cada membro e o nascimento de um sentido inovador, resultante da totalidade do enunciado. (MOISÉS, 1999)

"As análises e interpretações acerca do assunto permitem acreditar que a metáfora não é exclusiva da linguagem literária". Ocorre, igualmente, na linguagem falada, talvez de forma tão abundante quanto nos textos literários. A diferença residiria no caráter assumido pela metáfora vulgar, cotidiana, e a metáfora utilizada com objetivos estéticos. Decerto que as trocas verbais entre as pessoas, no comércio social diário, podem estruturar-se em torno de metáforas esteticamente novas ou harmônicas, mas não se trata da tendência geral. Via de regra, a Linguagem falada recorre ao que se chama de metáforas mortas ou latentes, quer dizer, metáforas petrificadas, estereotipadas, tornadas clichês, vazias de sentido. Assim, por exemplo, ao dizer 'braço de cadeira', está-se usando uma metáfora estereotipada, diversa desta outra: 'O teu silêncio é uma nau como todas as velas pandas' (Fernando Pessoa), de nítido recorte estético.

\subsection{POÉTICA E RETÓRICA, DE ARISTÓTELES}

Como já dito,

as primeiras observações acerca do conceito de metáfora devem-se a Aristóteles: 'a metáfora consiste no transportar para uma coisa o nome de outra, ou gênero para a espécie, ou da espécie para o gênero, ou da espécie de uma para a espécie de outra, ou por analogia' (Poética, tr. De Eudoro de Sousa, s.d., 1457 b 6). Aristóteles voltou à matéria no livro III da Retórica, sobretudo nos capítulos iniciais, onde, a propósito do estilo adequado à arte oratória, procura sublinhar a função da metáfora: 'não há ninguém que na conversação corrente não se sirva de metáfora'; 'a metáfora é o meio que mais contribuiu para dar ao pensamento clareza, agrado'; 'as metáforas não devem ser tomadas de longe, mas de objetos que pertençam a um gênero próximo ou a uma espécie semelhante, de maneira que se dê um nome àquilo que até aí não o tinha e veja-se claramente que o objeto designado pertence ao mesmo 
gênero"; 'as metáforas são enigmas velados'; 'é mister que a metáfora seja tirada da analogia, que se aplique a ambos os termos e provenha de objetos pertencentes ao mesmo gênero' (tr. De Antônio Pinto de Carvalho, s.d., p. 209, 211 e 217)" (MOISÉS, 1999, p. 326-327).

\subsection{COMUNICAÇÃO EM PROSA MODERNA, OTHON M. GARCIA}

As motivações da metáfora compõem-se sob as similaridades presentes no mundo objetivo e a inaptidão de abstração absoluta, bem como sobre a pobreza relativa do vocabulário a disposição, visto a riqueza e a numerosidade das palavras e ideias a transmitir e o prazer estético da caracterização pitoresca.

Em síntese, a metáfora pode ser definida como a figura de significação (tropo) que consiste na afirmação de uma coisa $(A)$ ser a outra $(B)$, em razão de qualquer similaridade percebida pela essência entre um traço característico de A e o atributo predominante, atributo por excelência, de $\mathrm{B}$, de modo a excluir os outros secundários visto que não são convenientes à caracterização do termo próprio (A). Assim, como exemplo, entende-se que se tratando da pedra preciosa esmeralda, o atributo predominante é a sua cor verde, de brilho muito particular. Então, olhos com essa mesma tonalidade possibilitariam a associação por semelhança, da qual resultaria a metáfora: seus olhos (A) são duas esmeraldas (B). Se os dois termos - o comparado (a coisa A) e o comparante (a coisa B) - estão expressos, como nos exemplos precedentes, diz-se que é metáfora in praesentia; se apenas o termo comparante está explícito, trata-se de uma metáfora in absentia (ou pura, como também se diz): duas esmeraldas cintilavam-Ihe na face.

Sob a perspectiva formal, a metáfora é, essencialmente, uma comparação implícita, ou seja, exonerada de partículas conectivas comparativas (como, tal qual, tal como), assim como também não apresenta uma estrutura composta pelos verbos parecer, semelhar, assemelhar-se sugerir, dar a impressão de ou um equivalente desses (GARCIA, 1983). 


\subsection{SEMÂNTICA, DE STEPHEN ULLMANN}

Segundo Ullmann (1961), a estrutura básica da metáfora é muito simples. "Há sempre dois termos presentes: a coisa de que falamos e aquilo com que a estamos a comparar". A coisa de que falamos seria o teor, aquilo com que a estamos a comparar seria o veículo. Já, ainda para o autor supracitado, o traço ou os traços que têm em comum denominar-se-iam de "fundamento da metáfora"

\subsection{A METÁFORA VIVA, DE PAUL RICOEUR}

A metáfora viva é uma investigação sobre a criatividade da linguagem e sua capacidade para incidir na realidade. Nessa obra, Paul Ricoeur inova sentidos por sua "impertinência semântica". Frente à referência habitual de um termo, a metáfora gera uma nova referência, e frente ao sentido literal, uma nova pertinência semântica, que se torna "impertinente" com respeito ao sentido literal. Para ele, a linguagem poética não é só um "outro modo" de dizer, mas é uma forma de "dizer mais", pois existe uma "mais-valia" de sentido gerada pelo trabalho semântico da metáfora (RICOEUR, 1975).

\subsection{MODERNA GRAMÁTICA PORTUGUESA, DE EVANILDO BECHARA}

Bechara (2002) diz que entre as causas que motivam a mudança de significação das palavras, uma das principais é a metáfora que consiste na translação de significado ocasionada pelo emprego em solidariedades, em que os termos implicados fazem parte de classes diferentes, sendo considerados, entretanto, pela combinação, como assimilados. Dando como exemplo:

Cabelos de neve, pesar as razões, negros pressentimento, doces sonhos, passos religiosos [...], boca do estômago, dentes do garfo, costas da cadeira, braços do sofá, pés da mesa, gastar rios de dinheiro, vale de lágrimas, o sol da liberdade, os dias correm, a noite caiu (BECHARA, 2002). 
Dessa forma, a metáfora não advém de uma comparação abreviada, como se é considerado tradicionalmente; ao contrário, é a comparação que consiste em uma metáfora explicitada. Também é importante que a metáfora linguística (linguisticamente originada pelo descompasso dos termos implicados nas solidariedades) seja distinguida da metáfora motivada extralinguísticamente pelo nosso saber sobre as coisas, como ocorre em expressões metafóricas do tipo não ponha a carroça adiante dos bois, a fim de se expressar a anástrofe incorreta de uma ação ou de um juízo. As metáforas são empregadas largamente na linguagem espontânea e na literatura, tendo nessa uma difusão entre os poetas simbolistas (BECHARA, 2002).

\subsection{GRAMÁtICA NORMATIVA DA LÍNGUA PORTUGUESA, DE ROCHA LIMA}

A Metáfora consiste na transposição de significados distintos sobre um determinado termo, em razão de uma comparação implícita. Ela se firma numa relação de similaridade, se embasando na mais natural das leis psicológicas: a associação de ideias. Na qual também aborda diversas modalidades, entre as quais vale ressaltar a personificação, a hipérbole, o símbolo e a sinestesia. (ROCHA LIMA, 1999).

\section{CONCLUSÕES PARCIAIS}

Acreditamos que o texto de Murilo Mendes é repleto de tipologias metafóricas e que as identificando e contextualizando-as, observaremos que as metáforas não ficam limitadas no espaço ideológico político-social e assim tais metáforas ultrapassariam esse espaço, constituindo-se como metáforas do sempre.

Percebemos que a metáfora não se trata simplesmente de um processo comparativo, seja ele implícito, seja explícito, mas de um processo mental que é a base da comunicação, da linguagem e do pensamento humano.

Sabemos que, seguindo a linha aristotélica, está a grande parte dos trabalhos sobre o assunto. Mattoso Câmara Jr., por exemplo, em seu Dicionário de linguística e 
gramática, define a metáfora como a figura de linguagem que transfere um termo para um campo de significados que não é o seu (CÂMARA, 1992). São também muitos os que, como o pensador grego, associam o fenômeno metafórico à comparação. Essa conceituação nos parece um tanto simplista, pois limita o fenômeno a trocas vocabulares. Cremos que com nossos estudos posteriores mostraremos que, embora a metáfora seja uma translação de significado procedente de uma associação por semelhança, sua ocorrência não se limita no transferir sentido de uma palavra para outra. Como bem descreve Othon M. Garcia, em sua Comunicação em prosa moderna, a metáfora fundamenta-se em dizer que uma coisa $(A)$ é outra $(B)$, quando qualquer similaridade é percebida entre algum traço característico de $\mathrm{A}$ e a característica predominante de $\mathrm{B}$ (atributo por excelência), de modo a excluir todos os outros aspectos secundários, visto que não são convenientes à caracterização do termo próprio A (GARCIA, 1983).

\section{REFERÊNCIAS BIBLIOGRÁFICAS}

BECHARA, Evanildo. Moderna gramática da língua portuguesa. Rio de Janeiro: Lucerna, 2002.

GARCIA, Othon, M. Comunicação em prosa moderna. 11. ed. Rio de Janeiro: FGV, 1983.

METÁFORA. Em: CÂMARA JR., J. Mattoso. Dicionário de linguística e gramática. 16. ed., Petrópolis, Vozes, 1992.

METÁFORA. Em: MOISÉS, Massaud. Dicionário de Termos literários. 14. ed. São Paulo: Cultrix, 1999.

METÁFORA. In: Dicionário Michaelis Eletrônico. Versão para assinantes UOL.

RICOEUR, Paul. (1975) La Métaphore Vive. Paris: Éditions du Seuil. Ed. Ut.: Ricoeur, P. (1983). A Metáfora Viva. Tradução. Porto: Rés Editora. 
ROCHA LIMA, Carlos Henrique da. Gramática normativa da língua portuguesa. Rio de Janeiro: José Olympio, 1999.

ULLMANN, Stephen. Semântica: Uma introdução à ciência do significado. Lisboa: Fundação Calouste Gulbenkian, 1961.

Enviado: Dezembro, 2020.

Aprovado: Dezembro, 2020. 